\title{
Arousal and Extension of Auspicious Culture in the Teaching Process
}

\author{
Haihong Xie \\ Eastern Art College \\ Zhengzhou Institute of Light Industry \\ Zhengzhou, China
}

\begin{abstract}
Chinese auspicious culture is the unique landscape and valuable wealth of national culture, and is the representation of soul of the Chinese nation. The new development of auspicious culture shows its achievement in modern design. It is the inescapable responsibility and obligation of college teachers to make expression with modern and international visual language, make China's national culture spread and developed in the modern design, and make the modern design present the wisdom of Chinese nation.
\end{abstract}

Keywords-auspiciousness; festivity; essence; traditional model; extension

\section{INTRODUCTION}

Chinese auspicious culture is a unique landscape of the oriental culture, and for thousands of years, the concept of the term of "auspicious" is continuously created and applied by the Chinese people in all kinds of events, and it is frequently presented in the real life by a certain form of expression.

As a contemporary college teacher, I have an urgent feeling: It is the inescapable responsibility and obligation of college teachers to blend the spiritual element of traditional auspicious culture into the teaching of modern design, arousing contemporary college students' love for the national culture, giving heritage and development, and bringing modern design with the embodiment of national wisdom.

Auspiciousness and festivity, congratulation on birthday and safety, is the eternal desire and pursuit of Chinese people for all ages. People often use the images of figures, flowers, animals, wares and fonts, the topics of auspicious expressions, proverbs, fairy tales and the performance techniques of metonymy, analogy, pun, symbolism and homophonous form to make a perfect combination of patterns and auspicious words and endow with the implication of good luck and elimination of disaster and difficulty, so to express a good wish and render a festive atmosphere. Chinese auspicious pattern is gradually formed in a long development process, and it is a unique art form created by our ancestors for pursuing a better life. It emphasizes a sense of structure in the law and life, rather than the lifelike copying of natural images. It is applied to express the people's pursuit and desire with the homophonic function of Chinese language. "A picture certainly has its implication that must be auspicious" highly summarizes the characteristic of auspicious patterns. Auspicious patterns has its beauty in a state of "All is understood and no words are necessary ", or "All is comprehended without being told". For instance, an upended "福" means "a blessing has come". Auspicious patterns are generally divided into four categories, including festivity, luck, great blessing and longevity, and the same auspiciousness in each category may be represented by a variety of patterns, so it brings charm for China's decorative art.

\section{Auspicious Culture IN CHINA}

The auspiciousness originally means a good omen. The auspicious is the blessing and good, the omen of a happy event". There is the saying of "if having no stray thought, you will realize the "way" and the luck and blessing will generate naturally" in the Zhuangzi. There is the sentences of "a lucky thing must have a good omen" in the On Zhouyi • Rhetoric. Auspiciousness is the blessing and expectation of the future life and the psychological desires and good wishes of Chinese nation for everything.

Auspicious concept originated in the primitive society, and auspicious awareness generated from the confusion and fear of the ancestors for human disease, pestilence, natural disasters and death and from the horror for hunting, killing and eating the living being. They need some force to help them expel the demons, eliminate the disasters, bless the safety. Thus the images that make the devil afraid are created, to become the patron saint of the clan. On the base, a large number of artistic images combining the features of human and animals and plants are created. These mysterious and wonderful icons become the most primitive form of religion, which is also the start of auspicious patterns, such as "Fig.1".

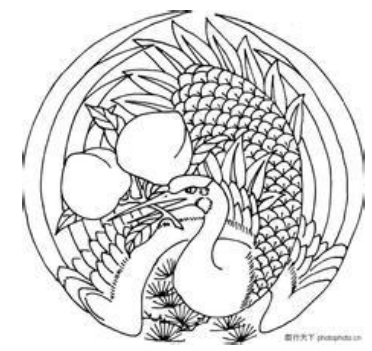

Fig. 1. The immortal crane in longevity 
Auspicious culture comes from wisdom of the Chinese people. The people not only created numerous auspicious characters, auspicious words, auspicious expressions and auspicious couplets, but also created a lot of auspicious mascot, auspicious substances and auspicious custom and auspicious figures to express their feelings and wishes. It has wide subject matter, rich content and various forms, and it is nonreplaceable for other art forms. Especially the auspicious graphic symbols and decorative patterns handed down in the history have a high value of reference and appreciation in the aesthetic field of art and design, and they have become the basis for the people to understand, apply and design auspicious signification, so to produce Chinese unique auspicious cultural phenomenon.

Auspicious graphics is an auspicious form of "an auspicious expression and a graphics" that mainly takes figures animals, birds and flowers, characters as the modeling image, the folk proverbs, auspicious expression and mythology as the theme, and the metaphor, analogy, pun, homophonous form and symbolism as the expression technique. Chinese auspicious patterns have rich content and wide subject matters, mainly including "blessing for happiness", "blessing for longevity", "festivity", "good luck" and so on.

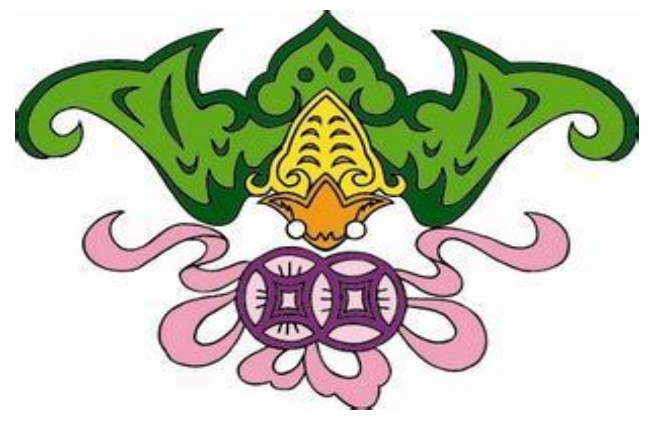

Fig. 2. Blessing in front (福在眼前)

Good fortune (福) is a major event in the minds and lives of Chinese people, and "blessing for good fortune" is the people's pursuit and longing for a happy life. Thus, in the process of cultural heritage, people deduced some graphics from their good wishes, to express the signification of blessing for good fortune in a fixed symbol. For instance, the bat (蝙蝠) in Chinese character is homonym of the "spreading all with the blessing (遍福)" in Chinese character, so the image of bat becomes a symbolic pattern of blessing after beautification, although the image of bat is not delightful for people. The pattern of “a Chinese character 寿 (longevity) circled by five bats around" means "offering longevity by infinite blessing (五福捧寿)"; the pattern composed by a bat and a ancient square-hole copper coin means "blessing in front (福在眼前)"; the pattern composed by the bat and the cloud design is called "blessing from the heaven (福字天来, 天降鸿福) "; the pattern of “a steed running with bats flying before it" means "a immediate blessing (马上得福)". Because of excess wealth, people get blessing, so blessing also means "surplus" and "lucky". Fish (鱼) in Chinese character has a homonym of "surplus” (余) in Chinese character, so the pattern with lotus and fish is called "surplus year after year (连年有余)", such as "Fig.2".

"Longevity" is a good wish of everyone. Yearning for longevity inspires people's imagination and creativity, so that many auspicious patterns of blessing for longevity formed. For instance, the patter of longevous tortoise and immortal crane (龟龄鹤寿图) has the implication and symbolization of longevity, as the saying of "crane of thousands of years and tortoise of millions of years" comes down from ancient times, so such a pattern means the longevity. Besides, everlasting pine, Magu (a longevous fairy) offering birthday present and so on all reflects the people's good wish for blessing for health and longevity. In addition, the longevity ( 寿) in Chinese character has hundreds of models that express a long life with an elongated “寿” and a healthy life with a rounded “寿”. The “寿” in combination with different substances will form various auspicious patterns, such as "everlasting pine of long years ", "more blessing and longevity," "evergreen pine and cypress" and "the heaven with longevity". Thus Chinese unique culture of longevity formed.

"Blessing for happiness (喜)" expresses the people's nice, delight and happy feeling. "Happy (喜)" itself is a Chinese character expressing delightful feeling. The auspicious patterns with "喜" include two forms: one is “喜”, called Double Happiness; the other is “禧”, deduced from the combination of “示” and “喜”. The two patterns both represent happy things coming with luck and celebration. Because of the “喜” in “喜鹊 (pied magpie)", pied magpie becomes an "omen" of happy events. There are patterns of "magpie on plum branch" and of "double magpies on plum branches". More the pomegranate contains a large number of pomegranate seeds, and when the pomegranate fruit splits open and the crystal jade-like pomegranate seeds are exposed, for which people give an imagery of "lighting up with pleasure", such as "Fig.3".

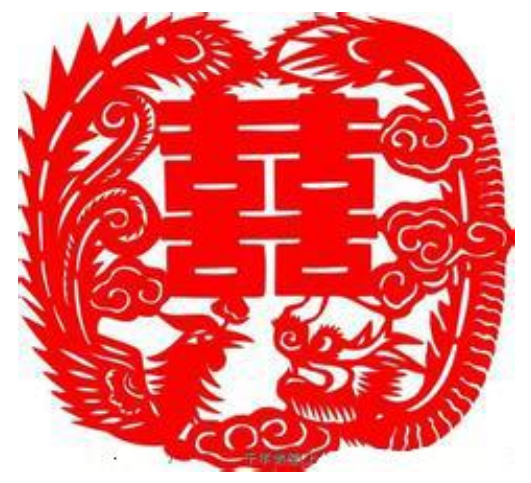

Fig. 3. The pattern of double “喜”

Luck also often takes the image of auspicious birds and animals as the symbol. Some fictitious animals such as dragon, phoenix and kylin do not exist in nature and they are built up in our mind by the people during overcoming the nature to be used to symbolize the power, mightiness, prosperity and peace. The patterns of dragon and phoenix include "prosperity brought by the dragon and the phoenix", 
"Two dragons are playing with a pearl ", "a flying dragon and a dancing phoenix", "a phoenix in morning sun". The patterns of kylin and clouds include "kylin offering a son" and "kylin offering riches and honour". An auspicious knot that is made with two forever-connected lines, expresses "a stretch without a break", "a life in endless succession" and "good luck as desired", such as: Panchang knot, Fangsheng knot and Ruyi knot. See "Fig.4".

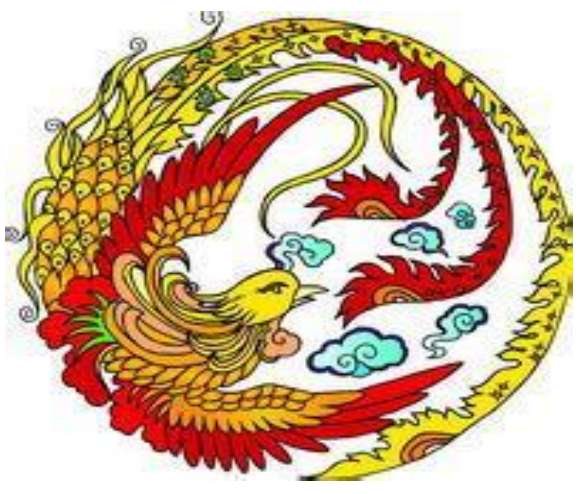

Fig. 4. The pattern of phoenix

\section{ChINA ' S TRAditional AUSPICIOUS PATTERNS IN THE MODERN LOGO DESIGN}

Chinese auspicious culture is not an occasional creation, and it contains constant processing and creation of generations of creators and has a long history of accumulation. It is the concentration of a large number of contents and humanistic spirit of Chinese traditional culture, and is the mirror of traditional cultural spirit. Especially for the signification of auspiciousness, it is not only the better desire of human for thousands of years but a better hope of the moderns for survival. The ancients put this meaning into graphics to express their wishes for a better life and the moderns apply it in their design to their yearning for the future. To show the festive atmosphere in the celebration of various social activities and express their wish of blessing, many Chinese graphic designers regard auspicious culture as their creative matters. This undoubtedly also brings a new problem, namely how to reasonably absorb more nutrition from the profound auspicious cultural connotation for recreation.

If only discovering from form rather than from the deep, we will only obtain the superficiality rather than the essence. In the posters of Macao's Return to the Motherland, The image of Lotus and the design originality of " Blooming Flowers and Full Moon " are applied to different extents to express the spirit and idea of the motherland's reunification, but most of them are mechanical graphic copying in from and simple graphic reproduction, without further interpretation of its connotation.

For a better extension and creation of auspicious arts in modern design, we should build a new national form. In the design and application of auspicious graphics, graphic designers should take shape and extend meaning after understanding and more make it vivid.

\section{A. The Reference of "Shape" Is Not a Simple Copying, but a Re-Creation of Traditional Shaping.}

Such re-creation is the reconstruction and application of some elements in auspicious pattern in the aesthetic concepts based on the understanding, to make it full of characteristic of the time and reflect the national character. In the extension of "shape", there are many good examples, such as the logo of Chinese Channel of Phoenix TV, which uses the image of a phoenix bird on pottery and the structure of Chinese auspicious patterns "Happy Meeting" in the form. The two subjects of a male phoenix and a female phoenix, a yin and a yang like two clusters of burning fire, are contained in a common circle with a very dynamic sense, which has visualizability and symbolic signification, reflecting a profound cultural background. While the a pair of relatively whirly wings of the phoenix bird have very dynamic sense, with the feature of male phoenix and female phoenix prominently opening their tails to make the two subjects connected into one and correlated each other. By the yin and yang integration of male phoenix and female phoenix, it indicates a historic conformity and recombination of Eastern and Western cultures and of traditional and modern cultures, reflects the modern media's characteristics, and also demonstrates the future prospects of "Phoenix" TV. See "Fig.5".

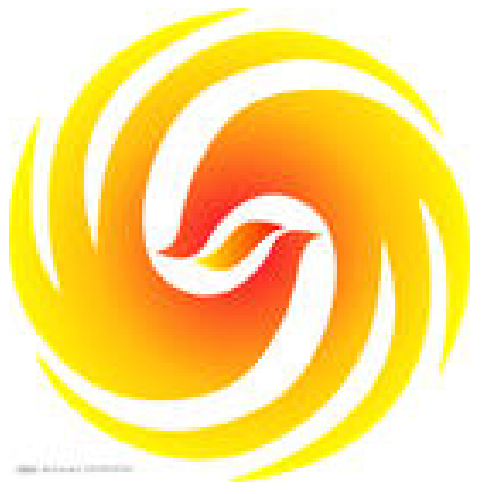

Fig. 5. The pattern of happy meeting

Another example is the logo of Xilun Daily Chemical designed by Cai Fulun, for which “喜” of "pied magpie “喜 鹊” in Chinese character" is used as the omen of a happy event. The designer designed the logo in a shape of lucky pied magpie image to make its traditional model kept completely and express the concept of festivity.

\section{B. The extension of meaning}

Chinese traditional graphics often implies a deeper symbolic "meaning" and the "meaning" behind auspicious patterns is the key for people to be fond of it, as the ancient or the modern have yearning for good things.

Thus the "meaning" of auspicious patterns is also used in modern design, applicable to pass the design ideas of the moderns. For instance, the logo of China Unicom used the 
shape and pattern of the auspicious knot that is derived from the "Panchang knot", one of Buddhist "Eight Auspiciousness", also called "Hua Wei" in Tibetan language. It is originally an ornament of nomads hanging on their waist, and afterward is gradually evolved into a decoration of clothing, musical instruments of Buddhists or Taoists, architecture and others, and endowed with the meaning of peace and harmony. Because the pattern made of countless “万 (®) " without beginning and end, commonly known as: "万字不断 (constant luck and long life)". In religion, it represents the permanence and eternity of Buddhist power, longing for no obstruction and marking the success of Buddha wisdom. The roundabout and to-and-fro lines symbolize the modern communication network, means the Unicom's telecommunications industry is orderly, fast and smooth in the society of information with a long and permanent prosperity" but also indicates Unicom has a lasting business, so that the meaning of Panchang knot is extended. See "Fig.6".

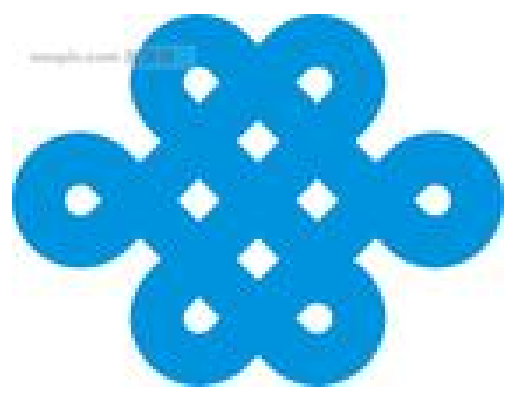

Fig. 6. The logo of China Unicom

In the logo, the four-square pattern means easy access and all the best, the six-circle pattern means easy and smooth access and the ten-cavity pattern means success and perfection. Whether in terms of symmetry or from even number, it is full of auspicious atmosphere that has been lost in the ancient Orient for a long time. China Unicom's logo also has two distinct "hearts" connected up and down that clearly shows the Unicom's purpose: for smooth communication with consilient idea, Unicom serves consumers with undivided attention forever.

And Chen Youjian has used an auspicious pattern of "Conjoined Children" as the logo of his work studio. Four Children has two heads, four hands and legs, forming an interesting picture of "four children scrambling for heads". This work has a beautiful appearance and a profound meaning. Legend says in the early Ming Dynasty, there was a genius, called Xie Jin. He has the reputation of "child prodigy", for he could read poetry and literature, paint and write articles at the age of five. Therefore, he was wellknown in his town and in the capital city. The emperor learned, and called him to the capital. The emperor tested him and said his reputation was well-deserved, and then asked him to study in the best school in his town. However, the teacher of that school didn't believe that such a little child could be full of learning, and he wanted to test him in person. That year was a bumper harvest year, so the teacher asked Xie Jin to paint a paint singing the bumper harvest. Xie Jin drew a picture of Ruyi Ganoderma, and the teacher said it was too worldly. He then drew another picture of $\mathrm{Nafu}$ Yingxiang, and the teacher said that it was too ordinary. Xie Jin then drew a picture of conjoined child with two heads. When the teacher saw it, he was very angry, and said: "we are all happy in such a good harvest year. Why do you draw a geek? How can you stick to the topic?" Xie Jin laughed and calmly replied: Four Happy Poem says: there are four major happy events in our life, having a welcome rain after a long drought, meeting an old friend in a distant land, the wedding night and succeeding in the government examination. What I drew is a conjoined child integrating four happy events in one picture. It is not only stick to the topic, but also fresh and interesting". The teacher listened and admired deeply. Since then, the auspicious pattern of "Four Happy Children" was spread all over the country, and it has been handed down to today. This logo pattern symbols the spirit of cooperation among designers, and also implies the close contact between the designer and the customer "Fig. 7 '.

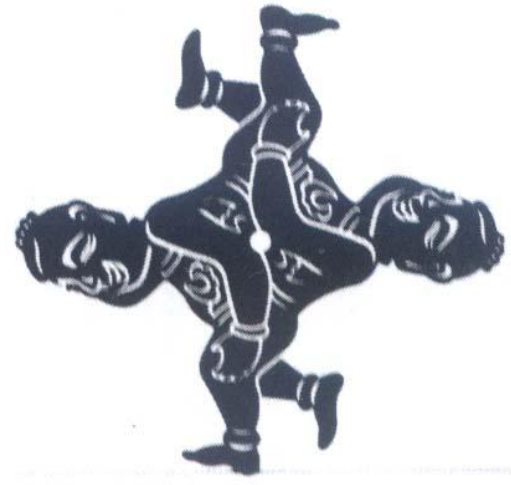

Fig. 7. Four Happy Children

\section{For the Use of Form And Meaning, It Can be Said to be the Shallow Development and Improvement of Tradition and the Creation of New National Form}

It needs us to explore in deeper field. We only have a deep understanding of the traditional spirit of art, can we find the coherence point of tradition and modern from high extraction and skillful combination of style of auspicious symbols, meaning, and charm, find out the extension of meaning and combine with modern aesthetic ideas, create new national forms in line with the new era, and receive the recognition of the international community. For example, the bid logo for 2008 Beijing Olympics designed by Han Meilin is a good example "Fig. 8". She didn't directly use traditional style, but used China's peculiar freehand brushwork to process our traditional lucky knot abstractly and get the best image. It has passed the two images of "Chinese knot" and "athletes" vividly. The logo not only contains full-bodied Chinese culture, but also conveys a good fortune of China's blessing, so it has been recognized by the world. 


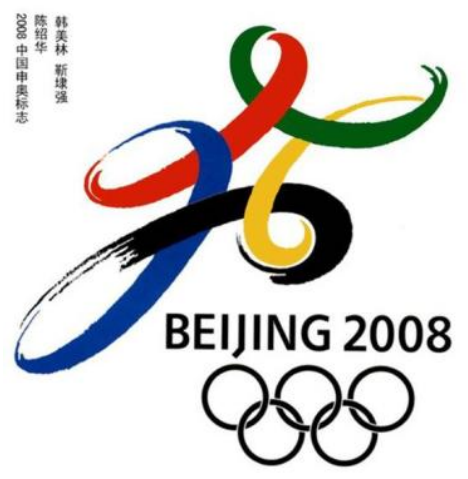

Fig. 8. Bid Logo for 2008 Olympics

\section{CONCLUSION}

In short, Chinese auspicious culture is a unique landscape in the national culture and the precious wealth depositing in the long historical river of national culture. It is the soul of the Chinese nation. Its new development symbolizes the auspicious culture shines in the modern design field. Therefore, on the basis of understanding, we use "form", extend "meaning" and pass down "spirit" in order to integrate the essence of Chinese national culture - the auspicious elements into modern education. We can use modern and international visual language to express it, so that China's national culture can take root among contemporary college students. It may arouse their love and passion for our traditional auspicious culture, so as to expand and develop excellent traditional culture, apply them in modern design and create new design with national culture.

\section{REFERENCES}

[1] Huang Qiangling. Discussion on Value Characteristic and Development of Modern Design Aesthetics [J].Art \& Design, 2004 (09)

[2] Zheng Guoxi. Application of Graphics in Advertising Design [J] Packaging Engineering. 2012.10: 36-39 